\title{
Deadly Outbreak of Iron Storage Disease (ISD) in Italian Birds of the Family Turdidae
}

\author{
Silvia PAVONE ${ }^{1) *}$, Sonia SALAMIDA ${ }^{1)}$, Ivan PECORELLI' ${ }^{2)}$, Elisabetta ROSSI ${ }^{3)}$ and Elisabetta MANUALI ${ }^{1)}$ \\ 1)Diagnostics and Animal Welfare Area, Istituto Zooprofilattico Sperimentale dell'Umbria e delle Marche, Italy \\ ${ }^{2)}$ Food Safety Division Area, Istituto Zooprofilattico Sperimentale dell'Umbria e delle Marche, Italy \\ ${ }^{3)}$ Diagnostic Specialist Area, Istituto Zooprofilattico Sperimentale dell'Umbria e delle Marche, Italy
}

(Received 12 March 2014/Accepted 9 May 2014/Published online in J-STAGE 11 June 2014)

ABSTRACT. A widespread deadly outbreak occurred in captive birds belonging to the family Turdidae in Italy. The present study was performed on 46 dead birds coming from 3 small decoy-bird breeders in central Italy. Only Turdus pilaris, Turdus iliacus, Turdus philomelos and Turdus merula were affected. No other species of bird held by these breeders died. A change of diet before the hunting season was reported from all breeders. Full necropsy of the animals and histological investigations of representative tissue samples were performed. Microscopical examination showed marked iron deposits in liver samples. Bacteriological investigations and molecular analysis to exclude bacterial and viral diseases were carried out. Contamination of food pellet samples by mycotoxins and analysis to detect heavy metal contaminants in food pellet samples were considered. An interesting result was the high iron content found in food pellets. It was higher than that considered suitable for birds, especially for species susceptible to development iron storage disease (ISD). Taken together, the results suggested an outbreak of ISD caused by the high iron content of food given to the birds before the hunting season. The high mortality recorded only in species belonging to the family Turdidae suggests a genetic predisposition in the affected birds. KEY WORDS: atomic absorption spectrophotometry (AAS), histology, iron storage disease (ISD), liver, Turdus spp

doi: 10.1292/jvms.14-0129; J. Vet. Med. Sci. 76(9): 1209-1212, 2014

Iron storage disease (ISD) is a basically life-threatening disease of captivity reported in several species of toucans (Rhamphastidae), mynahs (Sturnidae), birds-of-paradise (Paradisaeidae), curassows (Cracidae) and quetzals (Pharomachrus species) [4, 5, 7, 10, 27]. The pathogenesis of ISD is still poorly understood, and probably multifactorial causes should be taken into account. Several studies have been published on the key role played by dietary iron in hepatic iron stores $[5,6,12,21,23,25]$. Therefore, dietary modification is still considered an essential element in its treatment $[6,8,21]$. For this reason, although diets for birds should be formulated to contain between $50-100 \mathrm{mg} / \mathrm{kg}$ iron on a dry matter basis [23], levels of $50-65 \mathrm{mg} / \mathrm{kg}$ [5] or even lower levels $(30 \mathrm{mg} / \mathrm{kg})[7,8]$ were recommended for diets fed to susceptible species. As is well known, ISD refers to avian patients with clinical signs related to iron overload and altered organ function. In affected animals, an increased deposition of hemosiderin in different types of tissue, especially in the liver, heart and spleen, can be observed $[13,14,16,17,22,26]$. In particular, liver hemosiderosis is microscopically characterized by iron pigment overload in Kupffer cells and hepatocytes [4, 14]. Although iron accumulation with hemosiderosis may not always be associated

*Correspondence to: Pavone, S., Diagnostics and Animal Welfare Area of Istituto Zooprofilattico Sperimentale dell'Umbria e delle Marche, Via G. Salvemini, 1, 06126 Perugia, Italy.

e-mail: s.pavone@izsum.it

(C)2014 The Japanese Society of Veterinary Science

This is an open-access article distributed under the terms of the Creative Commons Attribution Non-Commercial No Derivatives (by-nc-nd) License $<$ http://creativecommons.org/licenses/by-nc-nd/3.0/>. with clinical disease, in severe cases, hepatic damage $[1,2]$ and heart failure $[3,21]$ may occur. Clinical signs commonly reported are not pathognomonic for diagnosis of ISD, and they reflect to end-stage malfunction of various organs in which iron has been accumulated. Common clinical signs of ISD include dyspnea, abdominal distension and ascites, weight loss and depression. Enlargement of the liver, heart or spleen is often observed, but hematology and serum biochemical analysis appear to be of little specific diagnostic value [20].

In humans, the most important iron overload syndrome is a hereditary condition called hemochromatosis [6].

\section{MATERIALS AND METHODS}

From October to January, a widespread deadly outbreak occurred in captive birds belonging to the family Turdidae in Italy. Six adult blackbirds (Turdus merula), 6 adult fieldfares (Turdus pilaris), 20 adult song trushes (Turdus philomelos) and 14 adult redwings (Turdus iliacus) were sent to the Diagnostics and Animal Welfare of Istituto Zooprofilattico Umbria e Marche for necropsy examination. Nineteen of the birds were male, and 27 were female. All animals came from 3 small decoy-bird breeders in central Italy. The mortality rates were $15 \%$ for fieldfares, $30 \%$ for redwings, $32 \%$ for song trushes and $14 \%$ for blackbirds. No other species of bird held by these breeders (Coccothraustes coccothraustes, Alauda arvensis and Fringilla montifringilla) died.

The breeders reported a recent change of diet before the hunting season. A commercial low iron $(25 \mathrm{mg})$ balanced diet specifically formulated to encourage singing birds was used. 

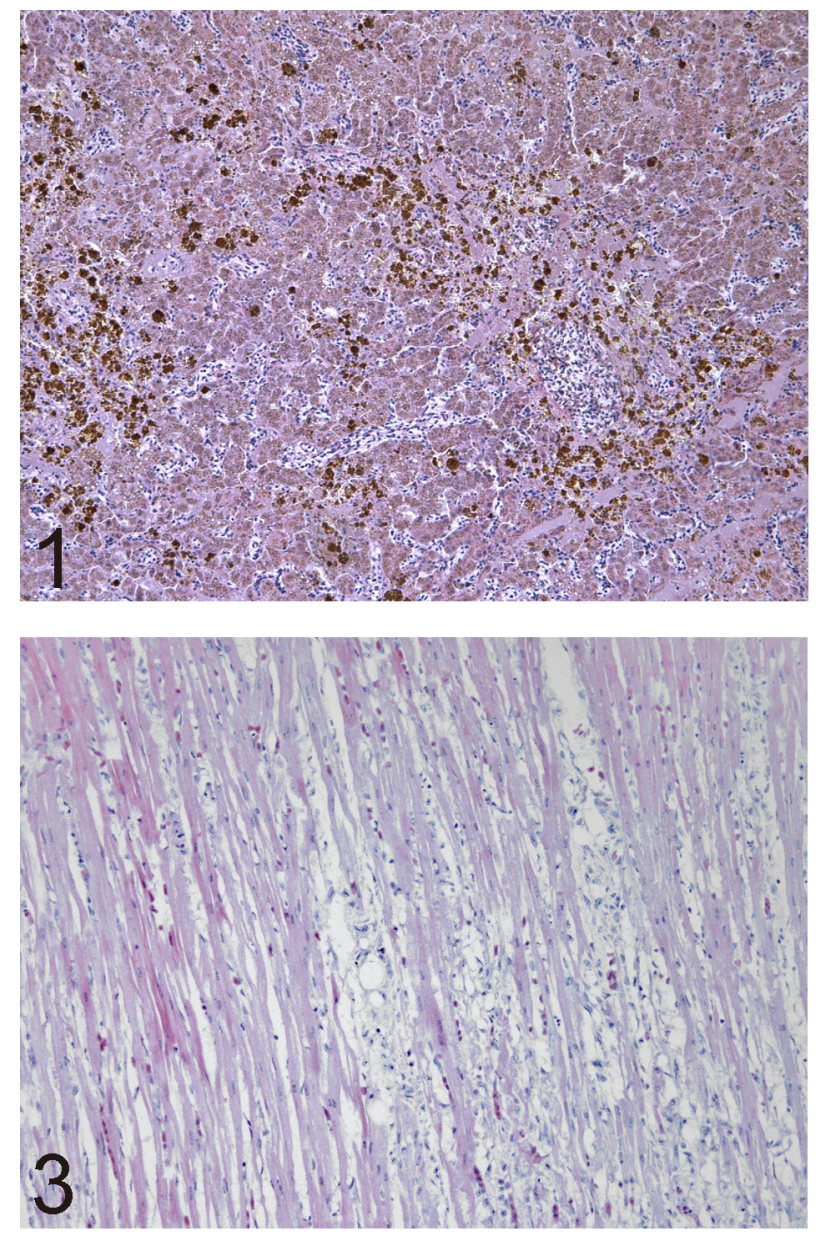

The clinical histories of all the dead birds included anorexia, lethargy and finally dyspnea and death. Further significant anamnestic data were not reported.

A full necropsy examination of all dead birds was performed, and representative tissue samples were removed and fixed in $10 \%$ neutral buffered formalin for routine histological examination. Hematoxylin and eosin, Masson's trichrome and Perls' Prussian blue staining were performed. During necropsy, fresh tissue samples from lungs, brain and intestines were collected and subjected to molecular analysis for Newcastle disease virus (NDV), avian influenza virus and West Nile disease virus. Viral RNA was extracted from the collected tissues using a QIamp Viral RNA Mini Kit (QIAGEN, GmbH, Hilden, Germany) according to the manufacturer's recommendation. The extracted RNA was store at $-80^{\circ} \mathrm{C}$ until use. A $316 \mathrm{bp}$ fragment of the fusion protein gene (F) of NDV was amplified from randomly transcribed cDNA using the primers NDVF-for2 and NDVF-rev1 [11]. PCR products of the expected size were verified by agar gel electrophoresis. A fragment of gene $M$ of avian influenza virus was amplified using a real-time one-step RT-PCR as previously described by Spackman et al. [24]. Two one-step real-time quantitative reverse transcription polymerase chain reaction (qRT-PCR) assays for the simultaneous detection

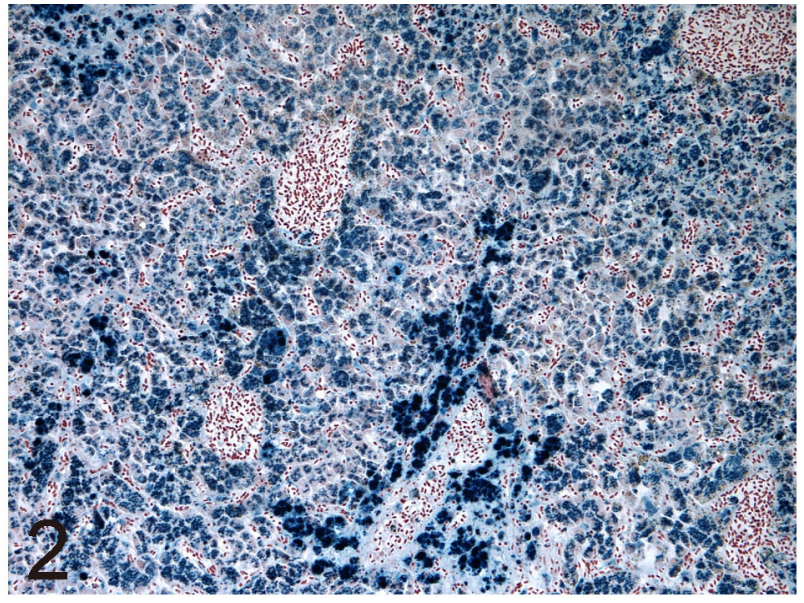

Fig. 1. Blackbird (Turdus merula). Liver with marked brown granular deposits consistent with hemosiderin localized especially in periportal hepatocytes $(\mathrm{H}-\mathrm{E}, \times 10)$.

Fig. 2. Blackbird (Turdus merula). Panlobular storage of large dark blue material considered to be iron deposits associated with severe hepatocytes sideronecrosis (Perls' Prussian blue staining, $\times 20$ ).

Fig. 3. Fieldfare (Turdus pilaris). Heart. Extensive myocardial necrosis characterized by fragmented myocardial fibers and mucoid edema with scant leukocyte infiltration $(\mathrm{H}-\mathrm{E}, \times 20)$.

of West Nile virus (WNV) lineage 1 and 2 strains were performed. The primers and probe for assay 1 targeted the 5 -untranslated region (UTR), whereas the amplicon for assay 2 was located in the nonstructural region NS2A, which enables an unambiguous and independent WNV diagnosis based on 2 different amplicons as described previously [9].

Intestinal and hepatic specimens were also aseptically collected for bacteriological examinations. Coprological examination of fresh stool specimens was also performed. Moreover, touch imprint (TI) cytology from heart and liver samples were prepared. These specimens were stained with a combination of May-Grünwald and Giemsa-Romanowsky stains, using a method described by Pappenheim [18]. Contamination of food pellet samples by mycotoxins (aflatoxin B1 - AFLB1, ochratoxin A - OTA and zearalenone - ZEA, fumonisin B1, B2 and B3) was investigated. AFLB1, OTA and ZEA were examined in a single chromatographic run by high-performance liquid chromatography (HPLC) coupled with a fluorimetric detection after purification by an immunoaffinity column (IAC) (Vicam AOZ, Milford, MA, U.S.A.). Samples were homogenized by preparation of a slurry with water at a ratio of 1:1.6 (w/v) and then extracted with ACN. The retention time (RT) was used for identification purposes, while concentrations of samples were calculated by interpo- 
lation with a calibration curve. Fumonisins B1, B2 and B3 as well also were determined by IAC (R-Biopharm Rhône P31). The feed samples were homogenized by preparation of a slurry with water at a ratio of 1:2.5 (w/v) and then extracted with $\mathrm{ACN} / \mathrm{MeOH}$. The purified extracts were analyzed by triple quadrupole LC-MS/MS (API 3200 QTrap) in MRM mode. For each molecule, two transitions were monitored (quantifier and qualifier). The retention time (RT) and ion ratio (IR) were used for identification purposes, while concentrations were calculated by interpolation with a calibration curve. Analysis of heavy metal contaminants in food pellet samples (iron $(\mathrm{Fe})$, copper $(\mathrm{Cu})$, zinc $(\mathrm{Zn})$ and lead $(\mathrm{Pb})$ ) was determined by atomic absorption spectrophotometry (AAS) with an air-acetylene flame after mineralization of the sample. Mineralization was carried out by a dry process. Ten grams of sample were incinerated in a muffle at $410 \pm$ $20^{\circ} \mathrm{C}$ for $6 \mathrm{hr}$. The ashes were treated with $10 \mathrm{ml} \mathrm{HNO} 3 / \mathrm{H} 2 \mathrm{O}$ $1: 1(\mathrm{v} / \mathrm{v})$. Subsequently, the sample was placed again in the muffle at $410 \pm 20^{\circ} \mathrm{C}$ until it was reduced to white ashes. The ashes were dissolved in $10 \mathrm{~m} l$ of $\mathrm{HCl} / \mathrm{H} 2 \mathrm{O} 1: 1(\mathrm{v} / \mathrm{v})$, and the volume was brought to $100 \mathrm{~m} l$ with water. The elements were determined by AAS at appropriate wavelengths.

\section{RESULTS}

At necropsy, all birds showed moderate to marked congestion and enlargement of the liver and spleen. The liver was found to be dark brown in color in around $10 \%$ of the birds. Moreover, the heart of some animals appeared enlarged, showing small well-demarcated, pale grayish areas consistent with necrosis. The necrosis involved mainly the apex and right ventricle.

Microscopic examination of liver samples showed venous congestion and severe, mainly periportal, parenchymal cell degeneration. Yellow/gold to brown granular pigment in the cytoplasm of hepatocytes consistent with hemosiderin was detected in all liver samples (Fig. 1). Necrosis of isolated hepatocytes was also observed. Perls's Prussian blue staining revealed a variable grade of iron deposits in liver samples. Forty percent of birds showed marked iron deposits in periportal (zone 1) hepatocytes; 50\% showed accumulation of iron in periportal and midzonal (zones 1 and 2) hepatocytes; $10 \%$ of birds showed marked panlobular iron deposits accumulation (zones 1, 2 and 3) (Fig. 2). Blackbirds showed the most severe iron accumulation, while song trushes appeared to be a less affected species. The levels of hemosiderosis in the livers of the investigated species are summarized in Table 1. Masson's trichromic staining did not

Table 1. Level of hemosiderosis in the livers of four investigated species

\begin{tabular}{lcccc}
\hline \multicolumn{1}{c}{ Iron deposits in } & Blackbirds & Fieldfares & $\begin{array}{c}\text { Song } \\
\text { trushes }\end{array}$ & Redwings \\
\hline Periportal & 0 & 1 & 14 & 3 \\
Periportal and midzonal & 2 & 4 & 6 & 11 \\
Panlobular & 4 & 1 & 0 & 0 \\
\hline
\end{tabular}

show hepatic fibrosis. Microscopical examination of heart samples showed acute myocardial necrosis characterized by small groups of eosinophilic and fragmented myocardial fibers in $37 \%$ of the birds examined (Fig. 3). Capillary dilatation and mucoid edema with scant leukocyte infiltration were also observed. Perls's Prussian blue staining revealed occasionally granular iron deposits in scattered myocardial cells. Iron deposits were also detected in tubular epithelial cells. No other histological lesions were observed. Analysis for Newcastle disease, avian influenza and West Nile virus showed negative results, as did bacteriological exams. Coprological examination of fresh stool specimens revealed coccidian oocysts of the genus Isospora in 36\% of the birds. Touch imprint cytology of heart and liver samples showed microfilariae in $13 \%$ of the examined birds. HPLC and IAC for evaluation of AFLB1, OTA and ZEA and Fumonisins B1, B2 and B3, respectively, in food pellets showed negative results. Analysis of heavy metal contaminants in food pellets by AAS revealed the following values: iron $111 \mathrm{mg} / \mathrm{kg}$; copper $6 \mathrm{mg} / \mathrm{kg}$; zinc $38 \mathrm{mg} / \mathrm{kg}$; lead $0.132 \mathrm{mg} / \mathrm{kg}$.

\section{DISCUSSION}

ISD is predominantly a disease of avian susceptible species that are highly efficient at absorbing dietary iron and do not downregulate iron absorption sufficiently when fed iron-rich diets [5, 26]. ISD is characterized by a massive accumulation of iron in the liver until heart failure, ascites, hypoalbuminemia and death occur [3, 12, 23]. In toucans (Rhamphastidae), mynahs (Sturnidae), birds-of-paradise (Paradisaeidae), curassows (Cracidae), quetzals (Pharomachrus species), tanagers and hornbills, hepatic iron overload associated with disease has been previously reported $[4,5,7$, 10, 13, 15, 27]. ISD in Turdus species has not been reported until now.

In this report, we described a sudden deadly outbreak in Italian birds of the Turdidae family. Firstly, Newcastle disease, avian influenza, West Nile fever and bacterial diseases were excluded by PCR and bacteriological exams. Considering the change of diet before the deadly outbreak, analyses of commercial diet for mycotoxins and metal contamination were performed. Analysis for mycotoxins with $H P L C$ showed negative results. On the other hand, analysis for heavy metal contaminants in food pellet samples showed a higher level of iron than that reported on the food label. Moreover, the iron content was higher than that considered suitable for birds [23]. In particular, it was three times higher than that recommended for feeding to iron-sensitive species $[7,8]$. Microscopical examination of the liver showed marked accumulation of iron characterized by a progressive involvement of hepatocytes from zone 1 to zone 3 . The blackbird seems to be more severely affected, showing marked panlobular iron deposit accumulation. On the other hand, the song trhush seems to be the least resistant species, showing a high mortality despite less marked iron deposition compared with the other investigated birds. However, clinical signs of ISD, usually considered expression of chronic liver damage [23], fibrosis, cirrhosis or neoplasms, were not 
detected in our birds. Conversely, acute liver damage represented by degeneration and necrosis of hepatocytes with iron overload (sideronecrosis) was constantly found. It is likely that the time required for these birds to develop hepatic chronic lesions has been too short and that acute liver and heart failure resulted in sudden death. Taken together, the results suggested an outbreak of ISD caused by a high iron content in the diet given before the hunting season. Since the environmental and nutritional conditions of the three small bird-decoy breeders were uniform, the mortalities that occurred only in blackbirds, fieldfares, song trushes and in redwing may suggest a predisposition of these species to development of ISD. Captivity-related stress and parasitism found in these birds could be considered possible co-factors triggering ISD $[3,19]$.

\section{REFERENCES}

1. Alt, E. R., Stemlib, I. and Goldfischer, S. 1990. The cytopathology of metal overload. Int. Rev. Exp. Pathol. 31: 165-188. [Medline] [CrossRef]

2. Bulte, J. W. M., Miller, G. F., Vymazal, J., Brooks, R. A. and Frank, J. A. 1997. Hepatic hemosiderosis in non-human primates: quantification of liver using different field strengths. Magn. Reson. Med. 37: 530-536. [Medline] [CrossRef]

3. Cork, S. C. 2000. Iron storage disease in birds. Avian Pathol. 29: 7-12. [Medline] [CrossRef]

4. Crissey, S. D., Ward, A. M., Block, S. E. and Maslanka, M. T. 2000. Hepatic iron accumulation time in European starlings (Sturnus vulgaris) fed two levels of iron. J. Zoo Wildl. Med. 31: 491-496. [Medline]

5. Dierenfeld, E. S., Pini, M. T. and Sheppard, C. D. 1994. Hemosiderosis and dietary iron in birds. J. Nutr. 124: 2685S-2686S. [Medline]

6. Dorrestein, G.M., Grinwis, G.M., Dominguez, L., Van de Jagt, E. and Beynen, A.C. 1992. An induced iron-storage disease syndrome in doves and pigeons: a model for hemochromatosis in mynah birds? pp.108-112. Proc. Annu. Conf. Assoc. Avian Vet.

7. Dorrestein, G.M., Mete, A., Lemmens, I. and Beynen, Jr. A. 2000 Hemochromatosis/iron storage: new developments. pp. 233-238. Proc. Annu. Conf. Assoc. Avian Vet.

8. Drews, A. V., Redrobe, S. P. and Patterson-Kane, J. C. 2004. Successful reduction of hepatocellular hemosiderin content by dietary modification in Toco Toucans (Ramphastos toco) With Iron-Storage Disease. J. Avian Med. Surg. 18: 101-105. [CrossRef]

9. Eiden, M., Vina-Rodriguez, A., Hoffmann, B., Ziegler, U. and Groschup, M. H. 2010. Two new real-time quantitative reverse transcription polymerase chain reaction assays with unique target sites for the specific and sensitive detection of lineages 1 and 2 West Nile Virus strains. J. Vet. Diagn. Invest. 22: 748-753. [Medline] [CrossRef]

10. Ensley, P.K. and Osborn, K. 1993. Hemosiderosis in a wild caught bird of paradise and other species in Papua New Guinea. p.27. Proc. Am. Assoc. Zoo. Vet.
11. Farkas, T., Antal, M., Sámi, L., Germán, P., Kecskeméti, S., Kardos, G., Belák, S. and Kiss, I. 2007. Rapid and simultaneous detection of avian influenza and Newcastle disease viruses by duplex polymerase chain reaction assay. Zoonoses Public Health 54: 38-43. [Medline] [CrossRef]

12. Gosselin, S. J. and Kramer, L. W. 1983. Pathophysiology of excessive iron storage in mynah birds. J. Am. Vet. Med. Assoc. 183: 1238-1240. [Medline]

13. Kincaid, A. L. and Stoskopf, M. K. 1987. Passerine dietary iron overload syndrome. Zoo Biol. 6: 79-88. [CrossRef]

14. Klasing, K. 1998. Minerals-iron. pp. 259-262. In: Comparative Avian Nutrition. Wallingford, United Kingdom: CAB International.

15. Lowenstein, L.J. 1986. Nutritional disorders of birds. pp.201212. In: Zoo and Wild Animal Medicine Current Therapy (Miller, R.E. and Fowler, M. eds.), WB Saunders, Philadelphia .

16. Lowenstine, L.J. and Munson, L. 1999. Iron overload in the animal kingdom. pp. 260-268. In: Zoo and Wildlife Medicine, Current Therapy 4 (Fowler, M.E. and Miller, R.E. eds.), WB Saunders, Philadelphia.

17. Lowenstine, L.J. and Petrak, M.L. 1978. pp.127-135. Iron pigment in the livers of birds. In: The Comparative Pathology of Zoo Animals (Montali, R. and Migaki, G. eds.) Smithsonian Press. Washington, D.C.

18. Lucas, A.M. and Jamroz, C. 1961. Atlas of Avian Hematology. Washington, United States Department of Agriculture, Agriculture Monograph. 25:271.

19. McDonald, D. 2002. Dietary considerations for iron storage disease in birds and implications for high vitamin A contents of formulated bird foods. pp.21-25. Proc. Joint Nutr. Symp.

20. Morris, P. J., Avgeris, S. E. and Baumgartner, R. E. 1989. Hemochromatosis in a greater Indian Hill mynah (Gracula religiosa): case report and review of the literature. J. Assoc. Avian Vet. 3: 87-92. [CrossRef]

21. Olsen, G. P., Russell, K. E., Dierenfeld, E. and Phalen, D. N. 2006. A comparison of four regimens for treatment of iron storage disease using the European starling (Sturnus vulgaris) as a model. J. Avian Med. Surg. 20: 74-79. [CrossRef]

22. Randell, M. G., Patnaik, A. K. and Gould, W. J. 1981. Hepatopathy associated with excessive iron storage in mynah birds. J. Am. Vet. Med. Assoc. 179: 1214-1217. [Medline]

23. Sheppard, C. and Dierenfeld, E. 2002. Iron storage disease in birds: speculation on etiology and implications for captive husbandry. J. Avian Med. Surg. 16: 192-197. [CrossRef]

24. Spackman, E., Senne, D. A., Myers, T. J., Bulaga, L. L., Garber, L. P., Perdue, M. L., Lohman, K., Daum, L. T. and Suarez, D. L. 2002. Development of a real-time reverse transcriptase PCR assay for type $\mathrm{A}$ influenza virus and the avian $\mathrm{H} 5$ and $\mathrm{H} 7$ hemagglutinin subtypes. J. Clin. Microbiol. 40: 3256-3260. [Medline] [CrossRef]

25. Spelman, L. H., Osborn, K. G. and Anderson, M. P. 1989. Pathogenesis of hemosiderosis in lemurs: role of dietary iron, tannin, and ascorbic acid. Zoo Biol. 8: 239-251. [CrossRef]

26. Taylor, J. J. 1984. Iron accumulation in avian species in captivity. Dodo 21: 126-131.

27. Turner, R. 1994. Iron storage disease (hemochromatosis) in the curassow. Proc. Annu. Conf. Assoc. Avian Vet. 265-267. 